\title{
Die 'verleentheid' van die teoloog voor die teodiseeprobleem
}

\author{
IWC van Wyk
}

\begin{abstract}
Embarrassment of the theologian concerning the theodicy problem

Questions concerning human suffering need not be embarrassing to the theologian. The absence of God should not be a problem for the believing sufferer. God is never absent. His wrath over sin is just another aspect of his presence in the world. The cross is the proof of this statement. God is also not an unjust God, His righteousness comes forth from his grace, not from the rewarding of deeds. God's grace can aslo only be known through the theology of the cross. Suffering cannot be led back to God's punishment of specific sins. Suffering is due to the original sin and therefore the communio peccatorum needs the communio sanctorum desperately.
\end{abstract}

\section{INLEIDING}

Elke predikant kom êrens in sy bediening te staan voor die krisis waar hy ' $n$ antwoord moet gee op die volgende vrae: Waarom moes hierdie ramp my huisgesin getref het, of waarom moes my kind so jonk sterf, of waarom laat God my vrou so lank ly? Voor sulke vrae staan die teoloog stomgeslaan. Die rede; ons ken nie die antwoord op hierdie vrae nie. Tog, gelukkig, is dit nie al wat ons kan en hoef te sê nie.

Hierdie waarom-vrae word teologies tuisgebring onder die teodiseeprobleem, maar alleenlik dan wanneer daar geworstel word met die vraag hoe God en sy handelinge verstaan en/of geregverdig kan word in die lig van die lyding. Die teodiseeprobleem is dus die probleem wat met ' $n$ bepaalde Godsbegrip worstel. Hierdie artikel wil daarom ook primêr konsentreer op die Godsbegrip agter sekere oplossings en probleme en daarteenoor 'n Godsbegrip probeer ontwikkel wat hopelik vir sommiges minder problematies en van meer hulp sal wees.

\section{DIE AFWESIGHEID VAN GOD}

'n Geloofsprobleem waarteenoor altyd weer getuienis afgelê moet word, is die vermoedelike 'afwesigheid van God' in ' $n$ lydingsituasie. 
Die vrae: Waarom laat God my so ly? Hoekom genees Hy my nie? Hoekom laat Hy my nie sterf nie, ken ons almal alte goed.

Wat is nou eintlik die probleem? Is God glad nie by lydendes teenwoordig nie of gryp God nie in om die wense van die lydende te verwesenlik nie? Is die probleem dus die wese van God of die handelinge van God? Of is dit alles skynprobleme wat teruggevoer kan word na 'n valse geloof? Of handel dit oor'n onvolledige Godsverstaan?

Kan God en is God ooit werklik afwesig? Wolfhart Pannenberg het byvoorbeeld uitgewys dat die moderne God-is-dood teologie, wat gefundeer word op die veronderstelling dat God afwesig is in die moderne kultuur, op teologiese waninformasie berus. Hierdie teologie bedoel met die 'afwesigheid' van God die funksieloosheid van God of die irrelevansie van God vir die tegnologies-antroposentriese wêreldverstaan. Die veronderstelling dat God 'afwesig' is, bloot omdat $\mathrm{Hy}$ vir sekere mense geen funksie het nie, beteken volgens Pannenberg allermins dat God nie in hierdie wêreld en met diesulkes handel nie.

In die Bybel kondig die afwesigheid van God die nabyheid van sy gerig aan. God se gerig bestaan nie uit 'n willekeurige strawwery nie, maar daarin dat God die sondaar oorlaat aan sy sonde en die gevolge daarvan (Rom 1: 24-32). Omdat alle skepsels op die lewensonderhoudende nabyheid van God aangewese is, sê die Psalmis: 'Maar as $u$ u terugtrek, is dit klaar met hulle' (Ps 104: 29), en daarom bid die vrome ook: 'Moet tog nie van my af wegkyk dat ek word soos die wat sterwe nie' (Ps 143: 76). Wanneer God Homself dus verberg en die mense aan hulle willekeur oorlaat, is dit'n uitdrukking van Sy toorn (Ps 89: 47; Job 13: 24). So het ook die profeet Jesaja die verwerping van sy boodskap, die verborge-bly van God vir sy volk, as voorteken van die oordeel verstaan. Esegiël het in 'n visioen gesien hoe God uit die Jerusalemse tempel wegtrek en deur sy afwesigheid die tempel en die stad aan die verwoesting deur die Babiloniërs oorlaat. God was ook by die Golgotagebeure afwesig tydens die Godverlatenheid van Jesus in die nag van Goddelike oordeel wat Hy namens ons moes dra (vgl Pannenberg 1984: 9-24).

Dit is dus duidelik; Die 'afwesigheid' van God kan nie uitgelê word as die irrelevansie van God vir die mens nie. God handel ook deur sy selfonttrekking aan die mens. God se skynbare afwesigheid is beslis onder andere gerig oor die sondaar.

Kan ons werklik beweer dat God afwesig is, as ons wense nie op 'n bepaalde tydstip deur God verwesenlik word nie? Sekerlik kan dit nie beweer word nie. Die aanklag teen God dat Hy nie op 'n bepaalde wyse 
kan of wil ingryp nie (die teodiseeprobleem) kan nie teruggevoer word na die vermoede dat God afwesig is by (sommige) lydendes nie.

God is en bly die aanwesige God. Sy vermoedelike afwesigheid is slegs een wyse van sy aanwesigheid. Die bekendste voorbeeld hiervan is Jesus se uitroep aan die kruis: 'My God, my God, waarom het $\mathrm{U}$ my verlaat?' (Mark 15: 34). Ten spyte daarvan dat Jesus gedink het dat God Hom verlaat het, was Hy teenwoordig, handelend in sy 'vreemde werk', sy opus alienum (so het Luther: WA 1, 112, 24; 356, 39; 346, 19; 4, 87, 24 God se gerigshandeling beskryf). Jesus se waarom-vraag na die afwesigheid van God kan en moet onder andere beantwoord word met die kennis van God se oordeel oor die sonde.

God was nie by Jesus se dood afwesig nie. Hy was aanwesig in sy oordeel oor die sonde (vgl 2 Kor 5: 21; Rom 8: 3; Gal 3: 13). Hierdie afwesige aanwesigheid van God by Jesus aan die kruis, is nie ' $n$ teken van demoniese bloeddorstigheid nie, maar ' $n$ teken van God se liefde vir die sondaar. Die sonde van die mens bestaan daaruit dat die mens uit en vir homself lewe; dat hy hom van sy naaste en God afsluit en selfgeslote lewe. Die dood is egter die konsekwensie van die sonde (Rom 6: 23) en wel dood as die uiteindelike uit-sterf uit alle gemeenskap en as die verlies aan verhoudinge met God en die mens. Jüngel (1979: 75-120) noem die dood daarom tereg: 'völlige Beziehungslosigkeit'. Die dood moet wel as die innerlike konsekwensie van die sonde beskou word, maar die sonde as die verwerping van die gemeenskapswil van God is tegelyk ook die gerig van God. Die dood is so die gerigsdood. Deurdat lesus die gerigsdood op Homself geneem het, sê Joest (1984: 257):

... hat er das Nein, das Gott über das gegen seine Liebe gelebte Leben sprechen muss, angenommen und Gott gegen die Sünde der Menschen rechtgegeben. In seinem Kreuz ist dieses nein für alle Zeiten gegen alle menschliche Selbstgerechtigkeit und Selbstrechtfertigung aufgerichtet.

Die afwesigheid van God by die kruis is, agterna betrag, nie 'n liefdelose oorlaat van Jesus aan onmenslike lyding nie, maar sy liefdevolle oordeel oor die sonde van die wêreld. God se afwesigheid by die kruis moet nie die vermoede versterk dat God 'n apatiese wese is wat nie kan of wil ingryp in die lyding van mense nie. Sy afwesigheid moet eerder die geloof versterk dat God wat ook die God van die oordeel is (en moet wees as Hy waarlik God is), die mens nie aan die konsekwensie van sy sondigheid, naamlik die ewige dood, oorlaat nie, maar sy 
toorn intertrinitaries laat uitwoed deur sy Seun te laat sterf, om in liefde sy gelowiges te red van die ewige dood.

Vir die lydende persoon vandag beteken die kruiservaring van Jesus dat ons God nie kan aankla van magteloosheid of liefdeloosheid nie. Hy is nie magteloos as iemand sterf nie. Die gerig van die dood moet voltrek word. Hy is nie liefdeloos nie, want sy toorn word deur sy liefde oorwin. Lyding en dood bly deel van ons sondige bestaan, terwyl liefde en geregtigheid deel bly van God se oordeel oor die sondaar.

Die veelbesproke probleem van die 'afwesigheid van God' (vgl oa Moltmann 1976: 138-147 en Jüngel 1978: 55-138) waarmee gewoonlik bedoel word dat God of irrelevant of apaties ò magteloos is, word gekenmerk deur' $n$ verskraalde Godsbegrip. God was nie by Auschwitz nie en is nie in die kankersale van Bloemfontein afwesig nie. Hy is nie magteloos nie en hy is nie liefdeloos nie. Sterwendes en hulle mense moet egter leer om die sonde, die erfsonde en sy konsekwensies, asook God se toorn oor die sonde te ken. As hierdie realiteit weer ter sprake gebring kan word, sal die bitterheid en teleurgesteldheid in God verminder kan word, aangesien God se 'vreemde werk' in samehang met sy 'eintlike werk' aan die kruis gesien sal kan word.

\section{DIE LYDING VAN DIE REGVERDIGES/ONSKULDIGES - 'N KRISIS VIR GOD SE GEREGTIGHEID?}

Die raaisel dat 'goeie' mense moet ly, bly steeds een van die brandenste vraagstukke onder gelowiges. Een rede is dat talle mense glo dat die 'daad-gevolg-samehang', soos dit in die wysheidsliteratuur bekend geword het (vgl oa Schmid 1974: 64-90; Kutsch 1973: 197-214; Kaiser 1985a: 1-23), onvoorwaardelik vir hulle geld en dat die 'krisis' van die wysheid nie op hulle van toepassing gemaak kan word nie (vgl oa Gese 1974: 168-179). Dat die 'regverdige' ook beproef kan word, is vir talle mense 'n onmoontlikheid aangesien God se gerig net op 'skuldiges' gerig word en sy geregtigheid, soos die 'daad-gevolg-teorie' dit veronderstel, dus noodwendig betwyfel moet word (vgl Stock 1980: 240-256).

Die vraag na God se geregtigheid is ' $n$ baie ou probleem. Een van die hooftemas van die Ou Testament het hierdie aangeleentheid tot onderwerp. In die Ou Testament word daar van die veronderstelling uitgegaan dat God die regverdige beloon, bystaan en nooit in die steek laat nie (Ps 37). Daar is dus uitgegaan van die veronderstelling dat daar 'n noodwendige samehang bestaan tussen die daad, gesindheid en hou- 
ding van die mens en die gevolge en konsekwensies daarvan. Veral Spreuke 26: 27; 10: 4; 13: 23 en Psalm 7: 16 is sprekende voorbeelde hiervan.

Deur die loop van die geskiedenis was dit egter dikwels die geval dat gelowiges aan hierdie samehange getwyfel het. Dikwels kon die bidder geen grond vir sy lyding vind nie, geen relasie tussen sy doen en sy lot in die lewe vasstel nie, soos die Assiriese koning Assurbanipal (668-626) dit eenmaal uitgeroep het: 'Gott und Menschen, Toten und Lebendigen, tat ich Gutes. Warum sind (trotzdem) Krankheit, Herzeleid, Auszehrung und Verderben an mich Geheftet?' (SAG A 17, 269 soos aangehaal deur Kaiser 1985b: 163).

Om saam te vat: Daar waar God se geregtigheid in twyfel getrek word, tree die probleem van die onskuldig lydende na vore.

Is daar egter so iets soos onskuldig lydendes? Vanuit die $\mathrm{Ou}$ Testament is dit nie maklik uit te maak nie. Die Ou Testament getuig juis daarvan dat die straf van die ballingskap direk teruggevoer moet word na die skuld van die volk; na die ongeloof en sosiale ongeregtigheid. Hoe langer die ballingskap egter aangehou het, hoe meer het die vraag na God se geregtigheid teenoor sy volk na vore gekom. Die skuldiges was lankal dood en die nageslag het gesê:

Ons vaders het gesondig, maar hulle is nie meer daar nie, ons word gestraf vir hulle sondes. En: Bekeer U ons tot U, Here, dat ons bekeer kan wees, gee ons weer die bestaan van vroeër. Of het $\mathrm{U}$ ons heeltemal verwerp? Is U toorn oor ons so groot? (Klaagl 5: 7 en 21-22).

Die vraag na die geregtigheid van God en die kreet van die onskuld van die lydende nageslag kom pragtig na vore in dié bekende woorde van Esegiël 18: 2: 'Die vadere het suur druiwe geëet, maar die kinders se tande het stomp geword.'

Die geloofstradisie, die vergeldingsleer, het dus sy geloofwaardigheid verloor. Die een moontlike oplossing was die individualisering van die heilsverwagting. Psalm 1 is hiervan ' $n$ goeie voorbeeld. Ook Esegiël 18: 20 getuig van so 'n ontwikkeling. Hier is geen sprake meer van 'n kollektiewe skuld nie:

Die mens wat sondig, sal sterwe. 'n Seun sal nie die straf op sy pa se sonde dra nie, en 'n pa sal nie die straf op sy seun se sonde dra nie. Wie leef volgens my wil, sal die vrugte daarvan pluk. Wie goddeloos is, sal die straf daarvoor dra. 
Hierdie oplossing was ook nie 'n afdoende oplossing nie. Hiervan lê die Jobsprobleem getuienis af. Job worstel juis met die probleem van die lyding van die onskuldige en wel in die sin dat daar volgens hom geen noodwendige samehang tussen sy lyding en spesifieke sondes gerekonstrueer kan word nie (Job 9: 21). Die omgekeerde argument is vir Job ewe geldig, naamlik dat God toornig kan raak oor skuldiges en onskuldiges (Job 9: 22). Hierdie onverklaarbare handelinge van God en onbegrip oor die onregverdige lot van sy menswees het Job daartoe gebring om ' $n$ regstryd met God aan te knoop.

Job, soos bekend, het besef dat die eindige verstand nie daartoe in staat is om die Oneindige in sy werke te begryp nie. Hy het die aanklag teen God teruggetrek en het boete gedoen (Job 42: 6). Job het op die ou einde tog weer die oplossing van die dig-gedeelte van die boek aanvaar naamlik dat God nie onregverdig handel nie en so elke mens volgens sy doen en late vergeld (Job 34: 11). Daarmee saam het Job die teologie van die Godsrede, die insig, dat die wysheid van God agter die veelduidigheid van die wêreld verborge is, aanvaar (Job 36: 22-33; 37: 1, 24). Die Ou-Testamentiese wysheid het egter nie verder gegaan soos die 'Lofprysinge van Tobit' (in die 1ste derde van die 2 de eeu $v C$ in Jerusalem ontstaan) om ' $n$ teodisee te ontwikkel waardeur die ballingskap en die verstrooiing onder die volke geregverdig word nie:

Lobpreiset ihn, ihr Söhne, vor den Völkern, denn er hat uns unter sie zerstreut. Dort verkündet seine Grösse. En: Ich lobpreise ihn im Land meiner Gefangenschaft, und ich verkünde seine Macht und Grösse dem Volk der Sünde. Macht kehrt, ihr Sünder, und wirkt Geregtigkeit vor ihm. Wer weiss, ob er euch nicht (auch) gnädig ist und mit euch Erbarmen hat? (Tobit 13: 3.4a en 8 volgens die vertaling van Deselaers 1982: 13).

Die gekanoniseerde teologie het 'n antwoord na die omstrede geregtigheid van God nie in die rigting van 'n teodisee ('n regverdiging van die tragiek - synde die wil van God) gesoek nie. Die antwoord is gevind in die gedagtekompleks van die boek Prediker.

Prediker het ten spyte van sy radikale bevraagtekening van die vergeldingsleer (Pred 8: 14) tog weer teruggegryp op God se gerig. Hy kon nie meer die vermoedelike 'sedelike wêreldorde', wat die resultaat sou wees van die insigtelike verhouding tussen menslike daad en goddelike vergelding, verdedig nie, maar het tog besef dat God se geregtigheid nie buite sy oordeel om ter verduideliking gestel kan word nie. Prediker het uitgegaan van die 'verborgenheid' van God, wat 
teruggevoer kan word na sy onbegryplike gelukstoedelings aan mense (Pred 2: 26; 6: 2). God is dus vir Prediker nie manipuleerbaar op grond van menslike gesindhede nie. Sy handelinge kan nie in 'n kousaalsamehang gebring word tot die skuld en onskuld van mense nie. Hy bepaal op onbegryplike wyse die lot van goeies en slegtes (Pred 3: 11; 7: 14). God verwag van die mens om die lewe te geniet (Pred 11: 9) en om vanuit 'n kompromislose pligsetiek te lewe (Pred 9: 10), want ten spyte van sy 'verborgenheid' vir die mens tydens sy aardse lewe, moet die mens leef met die wete van die sekerheid en beslistheid van die oordeel van God:

Die slotsom van alles wat jy gehoor het, is dit: Dien God en gehoorsaam sy gebooie. Dit is wat van die mens gevra word. God sal rekenskap eis oor alles wat gedoen word, ook oor wat in die geheim gedoen word, of dit goed is of kwaad (Pred 11: 13-14).

Die vraag na God se geregtigheid word dus van hierdie punt aan, nog steeds in terme van God se oordeel behandel, maar nie meer hoe elke daad in terugblik vanuit sy konsekwensies aan God se seën of straf gekoppel word nie, maar hoe God vanuit sy ekskatologiese gerigshandeling oor die ganse doen en late van 'n mens oordeel.

By hierdie laaste ontwikkelingsfase van die Ou Testament het die Nuwe Testament dan ook aangesluit. Ook die Nuwe Testament het God se geregtigheid nie gekoppel aan die beloning van die 'onskuldige' nie, maar eerder aan die nuwe konsep van die geregtigheid op grond van barmhartigheid. Johannes 3: 17 sê 'God het nie sy Seun na die wêreld toe gestuur om die wêreld te veroordeel nie, maar sodat die wêreld deur Hom gered kan word." Hierdie redding van die skuldige vind plaas op grond van die soendood en opwekking van Christus. So kan met Lohse (1979: 85) gesê word:

Durch Kreuz und Auferstehung Christi ist die Sündenvergebung als der Freispruch der Rechfertigung bewirkt; das aber bedeutet, das in diesem Ereignis Gottes Gerechtigkeit offenbar geworden ist.

Met die begrip 'geregtigheid van God' word dus God se genade bedoel. Paulus begryp dit as God se barmhartigheid, wat alleen in die geloof ontvang kan word, sodat die sola gratia en sola fide onlosmaaklik saam hoort. Lohse het daarom reg as hy die 'geregtigheid van God' as 'n Genetivus auctoris (Lohse 1973: 223) beskryf. God se geregtigheid word 
dus as 'n gawe begryp. Geregtigheid word daarom nie uit die werke van die wet nie, maar alleen uit die geloof aan die gekruisigde verkry.

Belangrik bly egter die feit dat die Reformatoriese verstaan van God se geregtigheid nóú met die oordeel van God saamhang. Die Reformatore het dienooreenkomstig die forensiese regverdigingsleer uitgewerk. Dit kom daarop neer dat die mens gesien word in sy posisie voor God se gerig (in foro Dei). Nie sy selfoordeel of sy vroomheid beslis oor hom nie, maar alleen God as Regter. Voor hierdie Regter is en bly die mens ' $n$ sondaar. Maar danksy God se geregtigheid vind hy genade by God. Calvyn (III, II, 5 vv) sê dit pragtig:

Er wird vor Gottes Gericht als gerecht angesehen und ist um seiner Gerechtigkeit willen Gott angenehm. Denn die Ungerechtigkeit ist Gott zuwider, und deshalb kann der Sünder vor seinen Augen keine Gnade finden, sofern er Sünder ist und als solcher angesehen wird. Wo als Sünde ist, da tritt auch Gottes Zorn und Strafvergeltung hervor. . . Durch den Glauben dagegen wird der gerechtfertigt, der, vor der Werkgerechtigkeit ausgeschlossen, Christi Gerechtigkeit durch den Glauben ergreift; ist er mit dieser Gerechtigkeit Christi umkleidet, so erscheint er vor Gottes Blick nicht als Sünder, sondern gleich als gerecht. Unter 'Rechtfertigung' verstehe ich also schlicht die Annahme, mit der uns Gott in Gnaden aufnimmt und als gerecht gelten lässt. Ich sage nun weiter: sie beruht auf der Vergebung der Sünden und der Zurechnung der Gerechtigkeit Christi.

God se geregtigheid stig versoening en bewerk so die verlossing van sondes. So is dit veel meer as net 'n vergeldingsmag: Dit is die grond van die nuwe lewe in Christus. Die voltrekking van die goddelike geregtigheid is duidelik die teenpool van 'n vergeldingsteorie. Dit is die vrye daad van die goddelike genade. Die gerig oor die sonde is voltrek - nie aan die oortreder nie, maar aan Jesus Christus. In die kruis is vir ons dus die uiterste gerig en uiterste genade ineen geweef. Die belangrike vir ons diskussie is egter dit, soos Michel (1978: 111) dit stel:

Im Kreuz Jesu und in der Botschaft vom Kreuz liegt das Gericht Gottes über die Welt, die Enthüllung der Sünde des Menschen, die Strafgewalt Gottes, die dem zukünftigen Gericht voranläuft. Gerechtigkeit und Strafgewalt schliessen sich nicht aus.

Waarop dit alles neerkom, is die noodsaaklike besef, dat daar nie so iets 
is soos ' $n$ 'onskuldige lydende' nie. Ook kan die mees tragiese en onbegryplike gebeure nie vanuit 'n vergeldingsteorie verklaar en as 'sinvol' aanvaar word nie, maar dit moet ook gesien word as 'n toebedeling vanuit die verborge handelinge van God in die lig van die liefdeoorwinnende daad van die strafdraende kruis van Christus. Alleenlik hierdie 'vreemde geregtigheid' van God sal kan troos, aangesien dit sy toorn oor ons sondige bestaan sien teen die agtergrond van sy grondlose barmhartigheid. Lydende mense moet dus gehelp word om nie die spel te speel van selfregverdiging (egodisee) en so God aan te kla van onregverdigheid nie, of om God te probeer regverdig ('n teodisee) deur jouself te verdoem nie. Hulle moet geleer word om getroos te word en nie om te regverdig nie.

\section{LYDING AS STRAF OP ONS SONDES?}

Die keersy van die 'daad-gevolg-denke' kan net so problematies op mense se geloofslewe inwerk. Die vraag kom altyd weer na vore of byvoorbeeld kanker of die dood van 'n kind teruggevoer moet word na 'n spesifieke sonde. Jesus self is met hierdie vraag gekonfronteer. In Johannes 9: 1-3 en Lukas 1-5 is daar spesifiek aan Jesus gevra of daar 'n koussale verband vasgestel kan word tussen siekte, katastrofes en sondes van mense (peccatum actuale)?

Hierdie vraag kan nie sonder meer beantwoord word met die mening dat Jesus die vergeldingsdogma van die ouere wysheid oorwin het nie. Jesus se antwoorde is veel meer genuanseerd as 'n blote afwys van enige kousale verbande. Teen die agtergrond van Jesus se afwysing van die samehang van sonde en lyding, moet bemerk word dat daar talle uitsprake in die Skrif voorkom wat in 'n ander rigting dui. In Markus 2: 1-12 word wel 'n samehang veronderstel tussen verlam wees en sonde, want genesing word gekoppel aan sondevergewing. In die Lukaniese geskrifte word die stomheid van Sagaria teruggevoer na die sonde van sy ongeloof (Luk 1: 20) en die blindheid van Elimas na die straf van God op grond van sy teenstand teen die verkondiging (Hand 13: 11). In Johannes 5: 14 het Jesus self teen die samehang van sondes en straf gewaarsku toe hy die verlamde by Betesda gewaarsku het om nie weer te sondig nie, aangesien hernude sonde tot 'n erger (siekte-) straf kan lei.

In Johannes 9: 1-3 het Jesus wel die samehang van blindheid en sonde afgewys. Jesus het egter nie die samehang prinsipieel opgehef 
nie, maar slegs sy geldigheid ten opsigte van hierdie besondere geval betwyfel, net soos Hy die dodelikheid van die siekte van Lasarus bestry het. Jesus het daarop gewys dat hierdie blindheid daar is sodat die werke van God geopenbaar kan word. So sê Gewalt (1986: 105) daarom tereg:

So muss die Exegese von Johannes 9: 1-5 mit der Feststellung enden, dass die Verse die an sie gestellten Erwartungen nicht erfüllen. Jesus überwindet kein Vergeltungsdogma, sondern belehrt seine Jünger, dass im fall dieses Blinden die Warum Frage unangemessen ist, weil es um ganz ander Dinge geht.

Die enigste konklusie waartoe 'n mens kan kom, is dat daar in die Skrif geen eenduidige verklaring gegee word op 'n veelhoekige probleem nie. Soms word lyding wel teruggevoer na die sonde van mense en soms word so 'n samehang betwyfel. Die Nuwe Testament het dus ten opsigte van hierdie probleem nie verder gevorder as die boek Job nie. Daar het Job se vriende sy lyding ook probeer verklaar in terme van persoonlike skuld, terwyl Job self hierdie samehang betwyfel het (vgl oa Job 4, 31). Die enigste geloofsopbouende hantering van hierdie sy van die 'daad-gevolg-denke' lê daarin dat die samehang van die oersonde (peccatum originale) en lyding uitgewys sal word.

Die vraag is: Hoekom wil mense weet of daar 'n samehang is tussen 'n siekte, teëspoed, lyding en bepaalde sondes? In die meeste gevalle waar 'n nie-getroffene hierdie inligting wil weet, gaan dit vir hom om selfontlasting deurdat hy sy eie geregtigheidsgevoel wil bevredig deur die betrokkene en sy mense te belas. Waar die betrokke persoon self wil weet, gaan dit dikwels daarom dat hy opsoek is na 'n hulpmeganisme om ' $n$ fatalistiese wêreldverstaan mee te regverdig. (Ons is mos nou eenmaal uitgelewer aan die oordeel van God en ons kan niks daaraan verander nie!) Om die selfgeregtigheid, selfregverdiging en fatalisme teen te werk, moet ons terugkeer na die Paulinies-Augustynse opvatting van die erfsonde. Heinrich Greeven (1948: 11) het reg as hy sê:

Das NT sieht in der Krankheit selbst ein Symptom für einen dahinterliegenden Tatbestand: nach seiner Auffassung ist die Krankheit ganz allegemein ein Symptom dafür, dass der Mensch sich von Gott losgesagt hat.

Die betekenis van die leer oor die erfsonde lê vir ons daarin, dat hierdie leer siekes en gesondes, lydendes en nie-lydendes saambind. Beide is 
in dieselfde mate verlossingsbehoeftig. Daardeur word die vraag of individuele skuld die oorsaak van 'n siekte was, gerelativeer. Die gedagte dat sekere mense onder die toorn van God verval het, word so uitgeskakel. Die religieus-gemotiveerde isolering van mense wat getref is deur rampe en ellendes, word so opgehef. Bonhoeffer (1960: 74-77, $245,255)$ het tereg gesê dat die voorwaarde vir die sanctorum communio die integrasie in die communio peccatorum is (Bonhoeffer 1960: 74-77, $245,255)$. Dit is juis hier in die heilige gemeenskap, waar mense met serebraalverlamde kinders, mense wat alles deur die droogte verloor het, saam met die gemeenskap van sondaars vertroos kan word deur die teologie van die kruis, dat ons leer van die liefde van die verborge God. In hierdie verband sê die Confessio Augustana nav Johannes 9: 1-3:

Darum sind die Trübsalen und Anfechtungen nicht allzeit göttliches Zorns Zeichen, sondern man muss die Gewissen fleissig unterrichten, dass sie die Trübsal lernen gar viel anders ansehen, nämlich als Gnadenzeichen, dass sie nicht denken, Gott habe sie von sich gestossen, wenn sie in Trübsalen sein (CA XII, 158-160BSLK, 286f).

\section{Literatuurverwysings}

BONHOEFFER, D 1960. Sanctorum Communio. 3. Aufl. München: Kaiser.

CALVIN, J 1984. Unterricht in der christlichen Religion: Institutio Christianae Religionis: Nach der letzten Ausgabe übersetzt und bearbeitet von Otto Weber. Neukirchen.

DESELAERS, P 1982. Das Buch Tobit: Studien zu seiner Entstehung, Komposition und Theologie. Göttingen: (OBO 43.)

GESE, H 1974. Die Krisis der Weisheit bei Koheleth, in Vom Sinai zum Zion: Alttestamentliche Beiträge zur biblischen Theologie. München: Kaiser.

GEWALT, D 1986. Behinderung und Krankheit als Folge von Sünde. Pastoraltheologie 75, 96-115.

GREEVEN, H 1948. Krankheit und Heilung nach dem Neuen Testament. Stuttgart.

JOEST, W 1984. Dogmatik, Bd I: Die Wirklichkeit Gottes. Göttingen: Vandenhoeck. (UTB 1336.)

JÜNGEL, E 1978. Gott als Geheimnis der Welt: Zur Begründung der Theologie des Gekeuzigten im Streit zwischen Theismus und Atheismus. 3. Aufl. Tübingen: Mohr.

JÜNGEL, E 1979. Tod. Gütersloh: Gütersloher Verlaghaus. (CTB 339.)

KAISER, O 1985a. Dike und Sedaqa: Zur Frage nach der sittlichen Weltordnung, in Der Mensch unter dem Schicksal: Studien zur Geschichte, Theologie und Gegenwartsbedeutung der Weisheit. Berlin: De Gruyter.

KAISER, O 1985b. Von der Gerechtigkeit Gottes nach dem Alten Testament, in Der Mensch unter dem Schicksal, 154-181. Berlin: De Gruyter.

KUTSCH, E 1973. Hiob: Leidender Gerechter - leidende Mensch. KUD 19, 197-214.

LOHSE, E 1973. Die Gerechtigkeit Gottes in der paulinischen Theologie, in Die Einheit des Neuen Testaments: Exegetische Studien zur Theologie des neuen Testaments I, 207-227. Göttingen: Vandenhoeck. 
LOHSE, E 1979. Grundriss der neutestamentlichen Theologie. 2. Aufl. Stuttgart: Kohlhammer. LUTHER, M [1883]. WA = Kritische Gesamtausgabe (Weimarer Ausgabe).

MICHEL, O 1978. Der Brief an die Römer. Göttingen: Vandenhoeck. (KEK. Bd IV.)

MOLTMANN, J 1976. Der Gekreuzigte Gott: Das Kreuz Christi als Grund und Kritik christlicher Theologie. 3. Aufl. München: Kaiser.

PANNENBERG, W 1984. Die Erfahrung der Abwesenheit Gottes in der Modernen Theologie, in Pannenberg (Hrsg), Die Erfahrung der Abwesenheit Gottes in der modernen Kultur. Göttingen: Vandenhoeck.

SCHMID, HH 1974. Altorientalisch-alttestamentliche Weisheit und ihr Verhälnis zur Geschichte, in Altorientalische Welt in der Alttestamentlichen Theologie, 64-90. Zürich: Theologischer Verlag.

STOCK, K 1980. Gott der Richter: Der Gerichtsgedanke als Horizont der Rechtfertigungslehre. EvTh 40, 240-256. 